\title{
IL-17A Contributes to the Angiotensin II-induced Neurovascular Coupling impairment through Oxidative Stress
}

Jessica Youwakim

Université de Montréal

Diane Vallerand

Université de Montréal

Helene Girouard ( $\nabla$ helene.girouard@umontreal.ca )

Université de Montréal

\section{Article}

Keywords: IL-17A, Angiotensin , Neurovascular Coupling, Oxidative Stress

Posted Date: October 18th, 2021

DOI: https://doi.org/10.21203/rs.3.rs-956885/v1

License: (c) (i) This work is licensed under a Creative Commons Attribution 4.0 International License.

Read Full License 


\title{
IL-17A Contributes to the Angiotensin II-induced Neurovascular Coupling impairment through Oxidative Stress
}

\begin{abstract}
Hypertension, a multifactorial chronic inflammatory condition, is a risk factor for neurodegenerative diseases including stroke and Alzheimer's disease. These diseases have been associated with higher concentration of blood interleukin (IL)-17A. However, the role that IL17A plays in the relationship between hypertension and brain remains misunderstood. Cerebral blood flow regulation may be the crossroads of these conditions. Hypertension alters cerebral blood flow regulation including neurovascular coupling (NVC). In the present study, the effects of IL-17A on NVC in the context of hypertension induced by angiotensin (Ang) II will be examined. Our results show that the neutralization of IL-17A or the specific inhibition of its receptor prevent the Ang II- induced NVC impairment. These treatments reduce the Ang IIinduced cerebral oxidative stress. Tempol and NOX-2 depletion prevent NVC impairment induced by IL-17A. These findings suggest that IL-17A, through superoxide anion production, is an important mediator of cerebrovascular dysregulation induced by Ang II.
\end{abstract}

\section{INTRODUCTION}

Hypertension, now considered a chronic inflammatory condition, is the most prevalent and modifiable risk factor for neurodegenerative diseases including stroke and Alzheimer's disease ${ }^{1}$. However, although many studies have linked brain inflammation and cerebrovascular alterations with brain disorders ${ }^{2-5}$, the involvement of inflammation in the impact of hypertension on the brain remains largely unknown. Previous data from experimental model of hypertension have 
shown important alteration of cerebral blood vessels and cerebral blood flow (CBF) regulation including neurovascular coupling $(\mathrm{NVC})^{6-8}$. $\mathrm{NVC}$ is defined by an increase in $\mathrm{CBF}$ in response to neuronal activation. Since the brain has high energy needs, slight alterations of this mechanism can negatively impact cerebral protein synthesis and neuronal function ${ }^{9}$. Although the involvement of inflammation in hypertension and peripheral vascular injury is well documented, the impact on CBF regulation remains largely underinvestigated.

The impact of inflammation on NVC was previously revealed through anti-inflammatory treatments with Treg lymphocytes (CD4+/CD25+) or interleukin (IL)-10 in an experimental model of hypertension induced by mice chronic angiotensin (Ang) II perfusion. In this study, we have shown that these treatments prevent gliosis and cerebral oxidative stress ${ }^{6}$. Ang II plays a key role in inflammation and increases the activity of $\mathrm{T}$ effecter cells such as $\mathrm{T}$ helper 17 lymphocytes and gamma-delta T-cells, ${ }^{10,11}$ enhancing the production of pro-inflammatory cytokines, such as IL-17 $\mathrm{A}^{10,12}$. IL-17A can induce brain damage by acting directly on neurons ${ }^{13}$ or indirectly through disruption of the BBB and neurovascular functions ${ }^{14-17}$. We hypothesized that these effects could be achieved through oxidative stress, since nicotinamide adenine dinucleotide phosphate (NADPH)-oxidase, specifically NOX-2, derived reactive oxygen species are well known to promote cerebrovascular dysfunctions ${ }^{18-20}$ and to be involved in IL-17Ainduced vascular inflammation ${ }^{21}$.

IL-17A is involved in reduced resting CBF and NVC impairment induced by high salt diet in mice ${ }^{16}$. These findings raise the possibility that IL-17A may be involved in CBF impairment in other experimental models of hypertension. Therefore, we examined the role of IL-17A in the 
neurovascular dysfunctions induced by Ang II. To explore this question, we have characterized the impact of IL-17A on CBF regulation in Ang II-induced hypertensive mice. Then, the potential role of NOX-2 and the subsequent superoxide anion production were evaluated to explain how IL-17A impairs NVC.

\section{RESULTS}

Neutralization of IL-17A or inhibition of its receptor prevents the Ang II-induced NVC

\section{impairment}

To examine the involvement of IL-17A on neurovascular coupling (NVC) impairment induce by Ang II, IL-17A neutralizing antibody (Ab) was administered in mice in parallel with Ang II. As previously observed ${ }^{8}, \mathrm{CBF}$ increases in response to whiskers stimulations in Ang II hypertensive mice were significantly attenuated by $23.2 \%$ compared to their controls (Figure $1 \mathrm{~A}, \mathrm{C}, p<0.01$ ). Neutralizing IL-17A Ab prevents NVC impairment induced by Ang II (Figure $1 \mathrm{~A}, \mathrm{D}, p<0.01$ ) without changes in resting CBF (Figure 1B). IL-17A Ab does not elicit changes in cerebrovascular responses to neuronal stimulations in control mice.

We next examined whether the rescued cerebrovascular responses corresponded to a prevented increase in systolic blood pressure (SBP). In mice not receiving the IL-17A Ab, as

expected $^{10,22,23}$, Ang II significantly increased the SBP compared to its control at day 7 and 14. This increase in SBP is of 37.4 and $35.9 \mathrm{mmHg}$ respectively. IL-17A neutralization slightly attenuates the increase in SBP induced by Ang II at those same time point by 9.8 and $9.4 \mathrm{mmHg}$ (Supplemental Figure 2). 
In order to assess whether the IL-17A prevents NVC impairment through its receptor, mice received an IL-17A receptor antagonist (IL-17RA mAB) simultaneously with the chronic systemic administration of Ang II. Ang II attenuates the increases in CBF (13.6\%) in response to whiskers stimulations compared to the control sham mice $(18.3 \%)$ (Figure $2 \mathrm{~A}, \mathrm{C}, \mathrm{p}<0.01)$. Inhibiting the IL-17A receptor prevents the disruption of NVC induced by Ang II (18.6\%) (Figure $2 \mathrm{~A}, \mathrm{D}, \mathrm{p}<0.01$ ). The laser-Doppler probe was positioned to get similar resting $\mathrm{CBF}$ in between groups (Figure 2B). The receptor antagonist does not elicit changes in cerebrovascular responses in control mice.

Then, the effect of IL-17A receptor inhibition on the SBP increase induced by Ang II was determined. The mean SBP in mice receiving Ang II was significantly higher compared with controls at day 7 and 14 with an increase of 51.7 and $53.7 \mathrm{mmHg}$, respectively. Inhibition of the IL-17A receptor partially attenuated the increase in SBP induced by Ang II at those same day point by 11.4 and $10.1 \mathrm{mmHg}$. (Supplemental Figure 3).

\section{Neutralization of IL-17A or inhibition of its receptor prevents the superoxide anion}

\section{production induced by Ang II}

To determine whether the increase production of reactive oxygen species by Ang II is mediated by IL-17A, we investigated the effect of IL-17A Ab on superoxide anion production. As shown in Figure 3, the increased production of superoxide anion by Ang II seen in the somatosensory cortex $(\mathrm{p}=0.12)$ and in the lacunosum moleculare (LMol), dentate gyrus (DG), cornu ammonis 1 (CA1) and cornu ammonis $3(\mathrm{CA} 3)$ regions of the hippocampus $(\mathrm{p}<0.01)$ was prevented 
following IL-17A Ab administration $(\mathrm{p}<0.05)$. Moreover, the production of superoxide anion in hypertensive mice receiving IL-17A Ab does not differ from that of control mice (Sham) with or without the IL-17A Ab administration.

In the same manner, somatosensory cortex and in all regions in hippocampus (LMol, DG, CA1, CA3,) showed a higher production of superoxide anion in mice with chronic administration of Ang II. IL-17RA mAB administration normalized these levels to the same as those of control mice (Sham) with or without the IL-17RA antagonist (Figure 4).

\section{Tempol treatment or NOX-2 depletion prevents NVC dysfunction induced by IL-17A}

Since IL-17A neutralization and IL-17A receptor inhibition prevent NVC impairment and oxidative stress induced by chronic systemic administration of IL-17A, we tested whether superoxide anions mediate the effects of IL-17A on NVC. Mice were thus chronically treated with the antioxidant superoxide scavenger and superoxide dismutase (SOD)-mimetic Tempol. As shown in figure $5 \mathrm{~A}$ and $\mathrm{C}$, systemic IL-17A Rb administration reduced $\mathrm{CBF}$ increase in response to whiskers stimulations by $22.8 \%$ compared to controls $(p<0.01)$. Disruption of NVC by the IL-17A Rb is prevented by Tempol. CBF responses were not modulated by Tempol alone (Figure $5 \mathrm{~A}, \mathrm{D}, \mathrm{p}<0.05$ ). The resting $\mathrm{CBF}$ was similar in all groups (Figure $5 \mathrm{~B}$ ).

To better understand the mechanisms by which IL-17A induces cerebral oxidative stress, we investigated the implication of NOX-2, the isoform present in brain endothelial cells, microglia and astrocyte ${ }^{7,19,24}$, on NVC by using knock out mice (NOX-2 ${ }^{-/}$). As obtain previously, IL-17A $\mathrm{Rb}$ administration in WT mice attenuated the response to whiskers stimulations by $24.9 \%$ 
compared to control (Figure $6 \mathrm{~A}, \mathrm{C}, \mathrm{p}<0.05$ ). Interestingly, NOX-2-/- mice do not exhibit NVC impairment or change in resting $\mathrm{CBF}$ in response to IL-17A Rb administration (Figure $6 \mathrm{~A}, \mathrm{~B}, \mathrm{D}$, $\mathrm{p}<0.05)$. We next examined whether the rescue in cerebrovascular responses correspond to a decrease in systolic blood pressure (SBP) in NOX-2-/- mice. Results from Supplemental Figure $4 \mathrm{~B}$, shows that the deletion of the NOX-2 gene does not prevent the increase in SBP observed at day 7 in response to IL-17A Rb administration (151.4 mmHg in WT vs $152.0 \mathrm{mmHg}$ NOX-2/mice).

\section{Tempol treatment or NOX-2 depletion prevents superoxide anion production induced by}

\section{$\underline{\text { L-17A }}$}

We then tested the efficiency of Tempol and NOX-2 to normalize the superoxide anion production induced by IL-17A. Figure 7 shows a significantly higher production of superoxide anion in somatosensory cortex and all hippocampal regions (LMol, DG, CA1, CA3) $(\mathrm{p}<0.05)$ in mice receiving the IL-17A Rb. In those same regions, Tempol prevents these increases without modulating the resting superoxide levels. Similarly, NOX-2 $-2^{-/}$mice that received IL-17A Rb presented similar level of superoxide anion production in the somatosensory cortex and all regions of the hippocampus as in control mice (Figure $8, \mathrm{p}<0.05$ ).

\section{DISCUSSION}

Our major new findings are that IL-17A, through its receptor, IL-17RA, takes part in the NVC impairment induced by Ang II. This effect is obtained through a process mediated by the NOX2-induced superoxide anion production in the hippocampus and the somatosensory cortex as demonstrated by a treatment with Tempol and deletion of the gene coding for NOX-2. 
Ang II through the Ang II type 1 receptor $\left(\mathrm{AT}_{1} \mathrm{R}\right)$ signaling pathway is an important proinflammatory stimulus, triggering the production of cerebral and systemic proinflammatory cytokines $^{6,25-27}$ chemokines $^{28}$ and reactive oxygen species ${ }^{7,10,19,29-31}$. The presence of perivascular macrophages expressing AT1 receptors in the neurovascular unit led to the hypothesis that inflammatory factors may mediate the effect of Ang II. Perivascular macrophages depletion indeed rescued NVC in Ang II slow pressor hypertension ${ }^{32}$. The modulatory impact of cytokines on NVC was then demonstrated in the Ang model of hypertension ${ }^{6}$. In this study, the anti-inflammatory cytokine, IL-10, also prevented gliosis and cerebral oxidative stress ${ }^{6}$. Inversely, a systemic inflammatory state in mice characterized by higher circulating IL-17A levels and induced by a high salt diet, contributed to NVC impairment $^{16}$. In the present study, blocking IL-17A or its receptor prevented the NVC impairment observed in Ang II slow pressor hypertension. Overall, these results suggest an important contribution of IL-17A in NVC impairment in models of hypertension. However, the mechanism by which IL-17 impairs NVC remains to be established.

Previous reports have shown an important link between the effect of Ang II on peripheral endothelial function and IL-17 $\mathrm{A}^{10,33}$ characterized by a lower increase in blood pressure in Ang II-induced hypertensive mice receiving IL-17A Ab or IL-17RA mAB administration ${ }^{33}$ or in IL$17^{-/-}$mice ${ }^{10}$. Our results confirmed the reduction in blood pressure in mice receiving these treatments. However, these changes in blood pressure cannot explain the impact on NVC since it was previously demonstrated that the impact of Ang II on NVC is independent of its hypertensive effect ${ }^{8,27}$. 
A more probable mechanism by which Ang II exerts its deleterious actions on NVC would be by activating its AT1R, at least on endothelial cells and perivascular macrophages ${ }^{7,32}$, which subsequently lead to the production of reactive oxygen species ${ }^{7,19,24}$. In the periphery, blood vessels from IL-1 $17^{-/-}$mice preserved vascular function, decreased superoxide production, and reduced T-cell infiltration in response to Ang $\mathrm{II}^{10}$. Therefore, we hypothesized that IL-17A could also modulate NVC in Ang II-induced hypertensive mice through a similar pathway. Our results confirm increased superoxide anion production in the hippocampus and somatosensory cortex in the slow pressor model induced by Ang II. Interestingly, neutralizing IL-17A or inhibiting its receptor normalizes the superoxide anion production. These results match those observed in the periphery by Madhur et al ${ }^{10}$. Overall, these findings suggest that IL-17A is involved in the superoxide anion production induced by Ang II, but that it is part of the mechanism by which Ang II impairs NVC.

To demonstrate that IL-17A can impair the cerebrovascular response, we tested the effect of the IL-17A Rb on NVC. We first showed that IL-17A Rb administration impaired NVC in a dosedependent manner, where the $50 \mathrm{pg} / \mathrm{kg} / \mathrm{h}$ dose showed a decrease in CBF in response to whiskers stimulations similar to the one seen in Ang II-induced hypertensive mice. However, it is not clear to what extent, the chosen concentration corresponds to physiopathological levels observed in humans. The IL-17 levels in plasma of hypertensive participants varie substantially with the duration of hypertension, the antihypertensive medication and comorbidities ${ }^{34}$, and no study had established the link between IL-17 levels and end-organ damages. Thus, further studies with 
large clinical cohorts will be necessary to establish the levels of IL-17 associated with cerebrovascular dysfunctions.

Similarly to Ang II in the slow pressor model of hypertension ${ }^{35}$, IL-17A can cross the blood brain barrier and produce cerebral superoxide anion which can lead to cerebrovascular dysfunction ${ }^{15}$ Therefore, we investigated the role of oxidative stress in the IL-17A-induced NVC dysfunction. In this study, mice were treated with the antioxidant Tempol due to its ability to easily cross membranes and its stronger therapeutic effect compared with other frequently used antioxidants ${ }^{36}$. Tempol treated mice show a CBF response to neuronal activation similar to those observed in control mice, showing the impact of oxidative stress on neurovascular decoupling induced by IL-17A. This has been confirmed by the preventive effect of Tempol on cerebral superoxide anion production in IL-17A Rb administered mice. These results suggest that increased superoxide anion production is a key mediator of IL-17A-induced NVC impairment.

NADPH oxidase, specifically NOX-2, the isoform expressed in cerebral endothelial cells, microglia and astrocytes, is likely the main source of cerebral superoxide anion in Ang IIinduced hypertensive mice ${ }^{7,19,24}$. In addition, NOX-2/- mice are protected from the Ang II on $\mathrm{NVC}^{7}$, further confirming the role of oxidative stress on cerebrovascular dysfunctions. We thus investigated the importance of NOX-2 on cerebrovascular dysfunction and oxidative stress in response to IL-17A. Our results confirm that NOX-2 plays role in NVC impairment induced by IL-17A, showing a similar CBF responses to whiskers stimulations and superoxide anion levels in NOX-2-- mice compared with their corresponding wildtype. This coincides with results observed in mice aortic vascular smooth cells where IL-17A induced reactive oxygen species 
formation through NOX-2 activation ${ }^{21}$. However, even though a peripheral cardiovascular protection is possible, there was no difference in blood pressure between NOX-2-/ mice and their wildtype. This supports previous results where NOX-2-/ mice receiving similar doses of Ang II as in the present study $(764 \mathrm{ng} / \mathrm{kg} / \mathrm{min})$ do not present a lower systolic blood pressure ${ }^{37}$.

In conclusion, we have demonstrated that IL-17A, through superoxide anion production, is an important modulator of NVC impairment induced by Ang II. Taken together, our findings suggest that modulating the immune system and targeting inflammation in hypertension could be a promising approach for reducing cerebrovascular dysfunctions. Given that hypertension and chronic inflammation are important risk factors for stroke, vascular cognitive impairment and Alzheimer's disease, the results of this study could open the door for future investigations to examine the influence of the immune system and inflammation on brain degeneration.

\section{METHODS}

This article adheres to the Transparency and Openness Promotion (TOP) Guidelines. The corresponding author can provide all data, methods, and materials used to conduct the research upon reasonable request.

\section{$\underline{\text { Animals }}$}

The study was approved by the Committee on Ethics of Animal Experiments of Université de Montréal and performed in accordance with the guidelines of the Canadian Council for Animal Care and by the ARRIVE (Animal Research: Reporting of In Vivo Experiments). Ten- to twelveweeks-old C57BL/6 male mice from Charles River Laboratories (Saint-Constant, Canada) were housed individually in a temperature-controlled room with ad libitum access to water and a 
standard protein rodent diet (Tekland global 18\% protein rodent diet). Ten-weeks-old C57BL/6 male mice with a targeted genetic deletion of NOX2 (B6.129S-Cybbtm1Din/J; Stock No: 002365) and their controls were obtained from Jackson Laboratory (Main, USA). Given that female mice are protected from the deleterious effects of Ang II on cerebrovascular functions ${ }^{31}$, only male mice were used in this study. Following acclimatization, animals were randomly assigned to experimental groups.

\section{$\underline{\text { Drugs Administration }}$}

Osmotic minipumps (model 1002; Alzet, USA) containing Ang II (MilliporeSigma, USA) were implanted subcutaneously under isoflurane anesthesia as described previously ${ }^{38}$. Briefly, mice received bupivacaine hydrochloride (Marcaine; CDMV, Canada, $2 \mathrm{mg} / \mathrm{kg}$ s.c.) at the site of the incision before the osmotic pump implantation. Each osmotic pump delivered $600 \mathrm{ng} / \mathrm{kg} / \mathrm{min}$ of Ang II for 14 days. Control animals were sham-operated since no difference in cerebrovascular response was observed between mice with a sham surgery and those with an implantation of a saline-infused minipump in pilot experiments ${ }^{6}$. Starting on the day of the implantation, mice were injected intraperitonially (i.p.) every four days with an IL-17A neutralizing antibody (eBioMM17F3; eBioscience, $0.5 \mu \mathrm{g} / \mu \mathrm{L}$ ), a specific IL-17A receptor antagonist (PL-31280; Amgen, $0.5 \mu \mathrm{g} / \mu \mathrm{L})$, or an immunoglobulin $\mathrm{G}(\mathrm{IgG})$ isotype control $(0.5 \mu \mathrm{g} / \mu \mathrm{L}$ Invitrogen, Canada). This administration regimen was chosen based on prior studies on murine models of hypertension and atherosclerosis ${ }^{33,39,40}$.

In another group of animals, systemic infusion of $50 \mathrm{pg} / \mathrm{kg} / \mathrm{h}$ of mouse recombinant IL-17A (IL17A Rb; 421-ML/CF; R\&D system, USA) for 7 days was achieved via an osmotic minipump 
(model 1007D; Alzet, USA). Since no study has previously shown the effect of systemic infusion of IL-17A on NVC, a dose-response curve of IL-17A Rb on cerebrovascular responses was assessed. IL-17A Rb administration has shown a dose-dependent effect on CBF in response to whiskers stimulations, where the $50 \mathrm{pg} / \mathrm{kg} / \mathrm{h}$ dose showed a decrease in cerebrovascular response similar to the one seen in Ang II-induced hypertensive mice (Supplemental Figure 1). A subgroup of C57BL/6 mice were simultaneously treated with Tempol (4-hydroxy-TEMPO; Millipore Sigma, Canada; $1 \mathrm{mmol} / \mathrm{l}$ ) administered in the drinking water or its vehicle (regular drinking water). Treatment with Tempol started 2 days before the osmotic pump implantation and ended at the time of sacrifice (one week after surgery).

\section{Systolic blood pressure monitoring}

Systolic blood pressure was monitored in awake mice using tail-cuff plethysmography (Kent Scientific Corp, Torrington, CT). Mice were warmed on a heating pad preheated at $37^{\circ} \mathrm{C}$ for ten minutes before and during blood pressure recordings. Animals were habituated to the procedure three days before blood pressure assessment. Right before the implantation of osmotic minipump (day 0) and weekly until the NVC analysis, ten blood pressure assessment per mice were done and average. Blood pressure was monitored by the same person at the same time of the day.

\section{Neurovascular coupling}

Anesthesia was initiated with isoflurane (induction: 5\%, maintenance: $2 \%$ ) and maintained with $50 \mathrm{mg} / \mathrm{kg}$ of $\alpha$-chloralose i.p. (MilliporeSigma, USA) and $750 \mathrm{mg} / \mathrm{kg}$ of urethane i.p. (MilliporeSigma, USA). The depth of anesthesia was checked by testing corneal reflexes and motor responses to tail pinch. Mean blood pressure and blood sample collection for gases 
assessment were monitored through the catheterization of the femoral artery. Mice were artificially ventilated with a nitrogen/oxygen/ $\mathrm{CO}_{2}$ mixture through a tracheal intubation. Body temperature was maintained at $37^{\circ} \mathrm{C}$ throughout the experiment. $\mathrm{CBF}$ was monitored with a laser-Doppler probe (AD Instruments, USA) placed stereotaxically on the thinned skull above the whisker barrel area of the somatosensory cortex. The flowmeter and blood pressure transducer were connected to a computerized data acquisition system (MacLab; Colorado Springs, CO). Analysis of CBF responses began 30 minutes after the end of the surgery to allow blood gases to stabilize. Animals with a mean arterial blood pressure under $60 \mathrm{mmHg}$ and/or blood gases outside normal range (pH: 7.35-7.40; pCO2: 33-45; pO2: 120-140) were eliminated from the study. CBF responses to neuronal activity were evaluated by whiskers stimulations. Three whiskers stimulations sessions of one minute at $6 \mathrm{~Hz}$ were done on the contralateral side to CBF measurement. Three minutes resting periods were left between each stimulation. CBF values were acquired with the LabChart6 Pro software (v6.1.3, AD Instruments, USA). The percentage increase in $\mathrm{CBF}$ represents the peak $\mathrm{CBF}$ response relative to the resting $\mathrm{CBF}$ peak values during the 20 seconds before stimulations.

\section{Superoxide anion production}

Superoxide anion production was assessed by hydroethidine microfluorography as previously described $^{41}$. Hydroethidine (dihydroethidium) is cell permeable and is oxidized to become the fluorophore ethidium bromide that intercalates in double-stranded DNA ${ }^{42}$. Mice were anesthetized with sodium pentobarbital (100 mg/kg body weight, CDMV) and perfused transcardially with PBS, pH 7.4. Brains were carefully isolated, frozen on dry ice and stored at $80^{\circ} \mathrm{C}$ until further analysis. Frozen brains were cut with a cryostat $(20 \mu \mathrm{m})$ and brain sections 
were mounted on slides and stored at $-20^{\circ} \mathrm{C}$ overnight. The slides were air dried at room temperature for $15 \mathrm{~min}$ followed by $15 \mathrm{~min}$ on a slide warmer set at $45^{\circ} \mathrm{C}$. The slides were then immersed in a dihydroethidium (DHE) solution ( $2 \mu \mathrm{M}$, MilliporeSigma) dissolved in PBS at $37^{\circ} \mathrm{C}$ for $2 \mathrm{~min}$. The slides were rinsed in PBS for $5 \mathrm{~min}$ and dried on a slide warmer for 20 minutes before they were coverslipped with Fluoromount-G mounting medium (Southern Biotech, USA). Images were acquired using an epifluorescence microscope Leica DM2000 with the same acquisition parameters for all groups. Analysis of relative fluorescence intensity was done using the Image J software (version 1.53; National Institutes of Health). DHE results are expressed relative to the control group.

\section{$\underline{\text { Statistical analysis }}$}

Data analysis was performed with GraphPad Prism software (version 7.0, La Jolla, USA) and results are presented as mean $\pm \mathrm{SEM}$. $\mathrm{CBF}$ responses to whiskers stimulations, resting $\mathrm{CBF}$, superoxide anion production and systolic blood pressure analysis were evaluated with an ANOVA for factorial design with repeated measures followed by a Bonferroni post-test for multiple group comparisons. The dose-response whiskers stimulations curve, resting CBF and mean arterial pressure from supplemental Figure 1 were analysed using a one-way-ANOVA followed by Dunnet's post-test. Significance was set at $p<0.05$. Sample size per group is presented in the results section as well as in the figure legends. 


\section{REFERENCES}

1. Qiu C, Winblad B, Fratiglioni L. The age-dependent relation of blood pressure to cognitive function and dementia. Lancet Neurol 2005; 4(8): 487-499.

2. Saetre P, Emilsson L, Axelsson E, Kreuger J, Lindholm E, Jazin E. Inflammation-related genes up-regulated in schizophrenia brains. BMC Psychiatry 2007; 7(1): 46.

3. Dantzer R. Cytokine, sickness behavior, and depression. Immunol Allergy Clin North Am 2009; 29(2): 247-264.

4. Kaiser D, Weise G, Möller K, Scheibe J, Pösel C, Baasch S, Gawlitza M, Lobsien D, Diederich K, Minnerup J, Kranz A, Boltze J, Wagner DC. Spontaneous white matter damage, cognitive decline and neuroinflammation in middle-aged hypertensive rats: an animal model of early-stage cerebral small vessel disease. Acta Neuropathol Commun 2014; 2: 169.

5. Whitehead SN, Cheng G, Hachinski VC, Cechetto DF. Progressive Increase in Infarct Size, Neuroinflammation, and Cognitive Deficits in the Presence of High Levels of Amyloid. Stroke 2007; 38(12): 3245-3250.

6. Iulita MF, Duchemin S, Vallerand D, Barhoumi T, Alvarez F, Istomine R, Laurent C, Youwakim J, Paradis P, Arbour N, Piccirillo CA, Schiffrin EL, Girouard H. CD4(+) 
Regulatory T Lymphocytes Prevent Impaired Cerebral Blood Flow in Angiotensin IIInduced Hypertension. J Am Heart Assoc 2019; 8(1): e009372.

7. Kazama K, Anrather J, Zhou P, Girouard H, Frys K, Milner TA, Iadecola C. Angiotensin II impairs neurovascular coupling in neocortex through NADPH oxidase-derived radicals. Circ Res 2004; 95(10): 1019-1026.

8. Capone C, Faraco G, Park L, Cao X, Davisson RL, Iadecola C. The cerebrovascular dysfunction induced by slow pressor doses of angiotensin II precedes the development of hypertension. Am J Physiol Heart Circ Physiol 2011; 300(1): H397-407.

9. Xie Y, Mies G, Hossmann KA. Ischemic threshold of brain protein synthesis after unilateral carotid artery occlusion in gerbils. Stroke 1989; 20(5): 620-626.

10. Madhur MS, Lob HE, McCann LA, Iwakura Y, Blinder Y, Guzik TJ, Harrison DG. Interleukin 17 promotes angiotensin II-induced hypertension and vascular dysfunction. Hypertension 2010; 55(2): 500-507.

11. Caillon A, Mian MOR, Fraulob-Aquino JC, Huo KG, Barhoumi T, Ouerd S, Sinnaeve PR, Paradis P, Schiffrin EL. $\gamma \delta$ T Cells Mediate Angiotensin II-Induced Hypertension and Vascular Injury. Circulation 2017; 135(22): 2155-2162. 
12. Ohshima K, Mogi M, Jing F, Iwanami J, Tsukuda K, Min L-J, Higaki J, Horiuchi M. Roles of Interleukin 17 in Angiotensin II Type 1 Receptor\&\#x2013;Mediated Insulin Resistance. Hypertension 2012; 59(2): 493-499.

13. Zhang J, Ke KF, Liu Z, Qiu YH, Peng YP. Th17 cell-mediated neuroinflammation is involved in neurodegeneration of aß1-42-induced Alzheimer's disease model rats. PLoS One 2013; 8(10): e75786.

14. Wojkowska DW, Szpakowski P, Glabinski A. Interleukin 17A Promotes Lymphocytes Adhesion and Induces CCL2 and CXCL1 Release from Brain Endothelial Cells. Int $J$ Mol Sci 2017; 18(5).

15. Huppert J, Closhen D, Croxford A, White R, Kulig P, Pietrowski E, Bechmann I, Becher B, Luhmann HJ, Waisman A, Kuhlmann CR. Cellular mechanisms of IL-17-induced blood-brain barrier disruption. Faseb j 2010; 24(4): 1023-1034.

16. Faraco G, Brea D, Garcia-Bonilla L, Wang G, Racchumi G, Chang H, Buendia I, Santisteban MM, Segarra SG, Koizumi K, Sugiyama Y, Murphy M, Voss H, Anrather J, Iadecola C. Dietary salt promotes neurovascular and cognitive dysfunction through a gutinitiated TH17 response. Nat Neurosci 2018; 21(2): 240-249.

17. Kebir H, Kreymborg K, Ifergan I, Dodelet-Devillers A, Cayrol R, Bernard M, Giuliani F, Arbour N, Becher B, Prat A. Human TH17 lymphocytes promote blood-brain barrier 
disruption and central nervous system inflammation. Nature Medicine 2007; 13(10): 1173-1175.

18. Park L, Anrather J, Girouard H, Zhou P, Iadecola C. Nox2-derived reactive oxygen species mediate neurovascular dysregulation in the aging mouse brain. J Cereb Blood Flow Metab 2007; 27(12): 1908-1918.

19. Girouard H, Park L, Anrather J, Zhou P, Iadecola C. Angiotensin II attenuates endothelium-dependent responses in the cerebral microcirculation through nox-2-derived radicals. Arterioscler Thromb Vasc Biol 2006; 26(4): 826-832.

20. Liu W, Chen Q, Liu J, Liu KJ. Normobaric hyperoxia protects the blood brain barrier through inhibiting Nox2 containing NADPH oxidase in ischemic stroke. Med Gas Res 2011; 1(1): 22 .

21. Pietrowski E, Bender B, Huppert J, White R, Luhmann HJ, Kuhlmann CR. Proinflammatory effects of interleukin-17A on vascular smooth muscle cells involve NAD(P)H- oxidase derived reactive oxygen species. J Vasc Res 2011; 48(1): 52-58.

22. Zimmerman MC, Lazartigues E, Sharma RV, Davisson RL. Hypertension caused by angiotensin II infusion involves increased superoxide production in the central nervous system. Circ Res 2004; 95(2): 210-216. 
23. Capone C, Faraco G, Peterson JR, Coleman C, Anrather J, Milner TA, Pickel VM, Davisson RL, Iadecola C. Central cardiovascular circuits contribute to the neurovascular dysfunction in angiotensin II hypertension. $J$ Neurosci 2012; 32(14): 4878-4886.

24. Girouard H, Park L, Anrather J, Zhou P, Iadecola C. Cerebrovascular nitrosative stress mediates neurovascular and endothelial dysfunction induced by angiotensin II. Arterioscler Thromb Vasc Biol 2007; 27(2): 303-309.

25. Shi P, Diez-Freire C, Jun JY, Qi Y, Katovich MJ, Li Q, Sriramula S, Francis J, Sumners C, Raizada MK. Brain microglial cytokines in neurogenic hypertension. Hypertension 2010; 56(2): 297-303.

26. Shen XZ, Li Y, Li L, Shah KH, Bernstein KE, Lyden P, Shi P. Microglia participate in neurogenic regulation of hypertension. Hypertension (Dallas, Tex : 1979) 2015; 66(2): 309-316.

27. Iulita MF, Vallerand D, Beauvillier M, Haupert N, Ulysse CA, Gagné A, Vernoux N, Duchemin S, Boily M, Tremblay M-È, Girouard H. Differential effect of angiotensin II and blood pressure on hippocampal inflammation in mice. Journal of Neuroinflammation 2018; 15(1): 62 . 
28. Vital SA, Terao S, Nagai M, Granger DN. Mechanisms underlying the cerebral microvascular responses to angiotensin II-induced hypertension. Microcirculation 2010; 17(8): 641-649.

29. Silva TMD, Broughton BRS, Drummond GR, Sobey CG, Miller AA. Gender Influences Cerebral Vascular Responses to Angiotensin II Through Nox2-Derived Reactive Oxygen Species. Stroke 2009; 40(4): 1091-1097.

30. Jackman KA, Miller AA, Drummond GR, Sobey CG. Importance of NOX1 for angiotensin II-induced cerebrovascular superoxide production and cortical infarct volume following ischemic stroke. Brain Research 2009; 1286: 215-220.

31. Girouard H, Lessard A, Capone C, Milner TA, Iadecola C. The neurovascular dysfunction induced by angiotensin II in the mouse neocortex is sexually dimorphic. $\mathrm{Am}$ J Physiol Heart Circ Physiol 2008; 294(1): H156-163.

32. Faraco G, Sugiyama Y, Lane D, Garcia-Bonilla L, Chang H, Santisteban MM, Racchumi G, Murphy M, Van Rooijen N, Anrather J, Iadecola C. Perivascular macrophages mediate the neurovascular and cognitive dysfunction associated with hypertension. $J$ Clin Invest 2016; 126(12): 4674-4689. 
33. Saleh MA, Norlander AE, Madhur MS. Inhibition of Interleukin 17-A but not Interleukin-17F Signaling Lowers Blood Pressure and Reduces End-organ Inflammation in Angiotensin II-induced Hypertension. JACC Basic Transl Sci 2016; 1(7): 606-616.

34. Simundic T, Jelakovic B, Dzumhur A, Turk T, Sahinovic I, Dobrosevic B, Takac B, Barbic J. Interleukin 17A and Toll-like Receptor 4 in Patients with Arterial Hypertension. Kidney and Blood Pressure Research 2017; 42(1): 99-108.

35. Biancardi VC, Son SJ, Ahmadi S, Filosa JA, Stern JE. Circulating angiotensin II gains access to the hypothalamus and brain stem during hypertension via breakdown of the blood-brain barrier. Hypertension 2014; 63(3): 572-579.

36. Luo Z, Chen Y, Chen S, Welch WJ, Andresen BT, Jose PA, Wilcox CS. Comparison of inhibitors of superoxide generation in vascular smooth muscle cells. Br J Pharmacol 2009; 157(6): 935-943.

37. Murdoch CE, Alom-Ruiz SP, Wang M, Zhang M, Walker S, Yu B, Brewer A, Shah AM. Role of endothelial Nox2 NADPH oxidase in angiotensin II-induced hypertension and vasomotor dysfunction. Basic Res Cardiol 2011; 106(4): 527-538.

38. Duchemin S, Belanger E, Wu R, Ferland G, Girouard H. Chronic perfusion of angiotensin II causes cognitive dysfunctions and anxiety in mice. Physiol Behav 2013; 109: $63-68$. 
39. Cheng X, Taleb S, Wang J, Tang TT, Chen J, Gao XL, Yao R, Xie JJ, Yu X, Xia N, Yan XX, Nie SF, Liao MY, Cheng Y, Mallat Z, Liao YH. Inhibition of IL-17A in atherosclerosis. Atherosclerosis 2011; 215(2): 471-474.

40. Madhur MS, Funt SA, Li L, Vinh A, Chen W, Lob HE, Iwakura Y, Blinder Y, Rahman A, Quyyumi AA, Harrison DG. Role of interleukin 17 in inflammation, atherosclerosis, and vascular function in apolipoprotein e-deficient mice. Arterioscler Thromb Vasc Biol $2011 ; 31(7):$ 1565-1572.

41. Sadekova N, Vallerand D, Guevara E, Lesage F, Girouard H. Carotid calcification in mice: a new model to study the effects of arterial stiffness on the brain. J Am Heart Assoc 2013; 2(3): e000224.

42. Münzel T, Afanas'ev IB, Kleschyov AL, Harrison DG. Detection of superoxide in vascular tissue. Arterioscler Thromb Vasc Biol 2002; 22(11): 1761-1768.

Figures and Figure legends : 

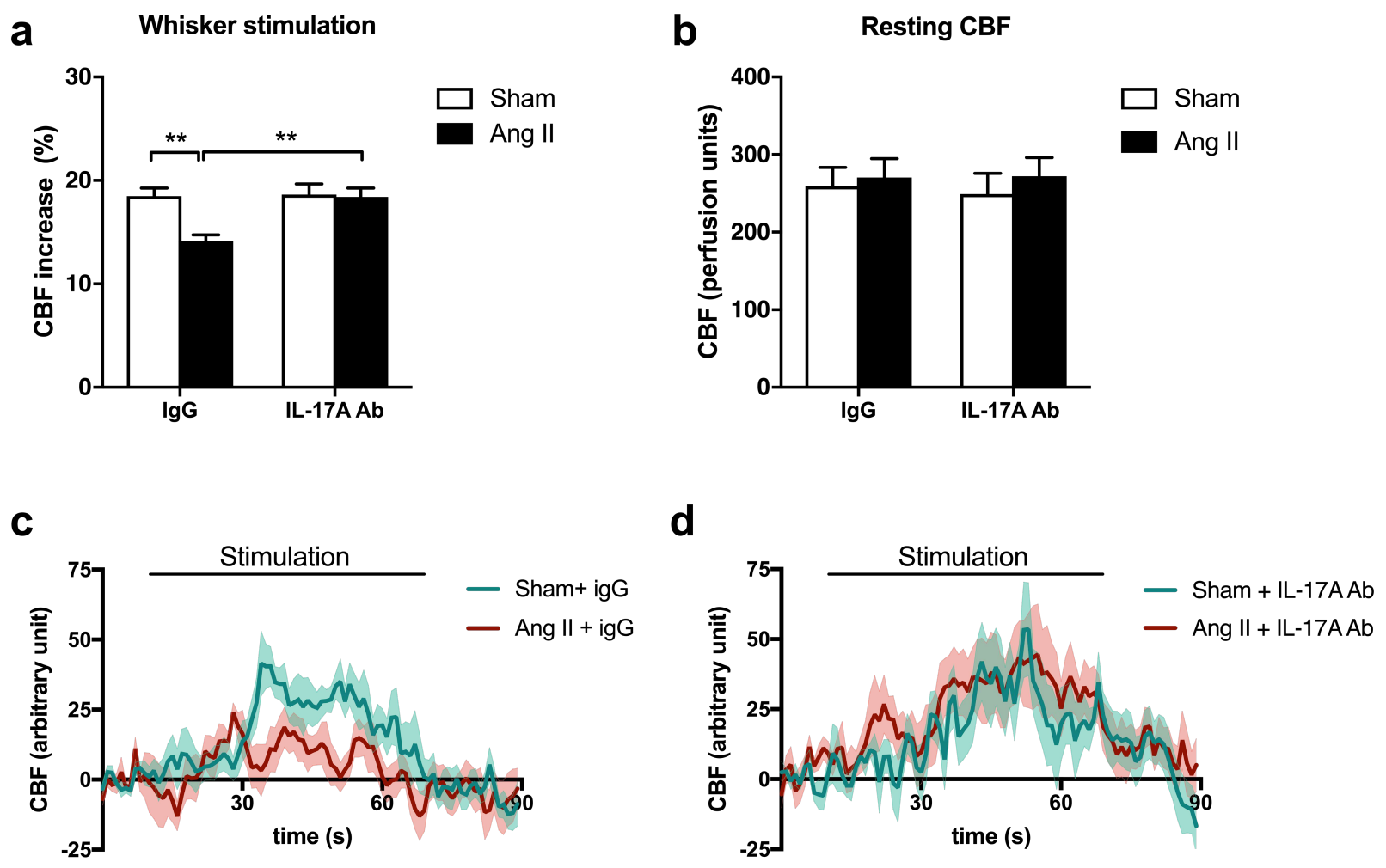

Figure 1: IL-17A neutralization prevents neurovascular coupling impairment induced by

Ang II. Cerebral blood flow (CBF) in response to whiskers stimulations measured in vivo by laser Doppler flowmetry in C57BL/6 male mice treated with an anti-IL-17A neutralizing antibody (IL-17A Ab) or control mouse immunoglobulin $\mathrm{G}(\mathrm{IgG})$ antibody $(0.5 \mu \mathrm{g} / \mu \mathrm{L}$ per mouse every 4 days, i.p.). This administration started at day 0 of Ang II (600 ng/kg/min, 14 days) infusion through an osmotic minipump or sham surgery. The graphs depict (a) CBF as percentage changes with respect to the initial CBF value, (b) resting CBF value and (c, d) represent 1 second average curves of the evoked CBF, expressed in arbitrary unit. SEM is represented by the lighter tone shade surrounding each curve. Data were analysed using ANOVA for factorial design followed by a Bonferroni post-test. $* * \mathrm{p}<0.01, \mathrm{n}=10-12$ per group. 
a



C

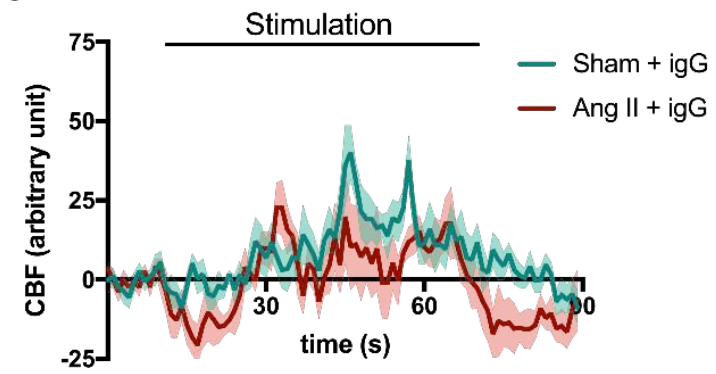

b Resting CBF

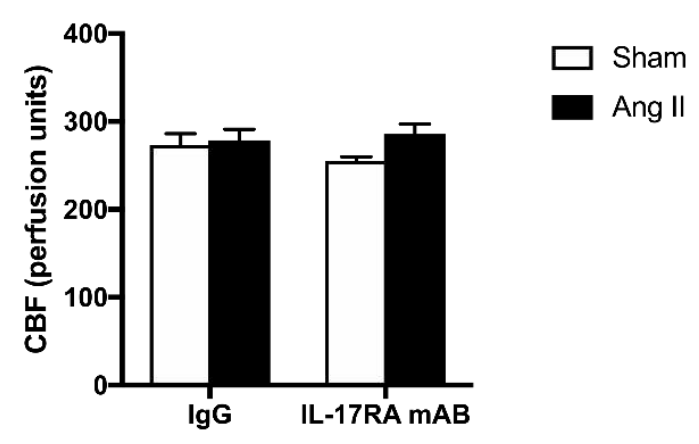

d



Figure 2: IL-17A receptor inhibition prevents Ang II-induced neurovascular coupling alteration. Cerebral blood flow (CBF) in response to whiskers stimulations measured in vivo by laser Doppler flowmetry in C57BL/6 male mice treated with an IL-17A receptor antagonist (IL17RA mAB) or control mouse immunoglobulin $\mathrm{G}(\mathrm{IgG})$ antibody $(0.5 \mu \mathrm{g} / \mu \mathrm{L}$ per mouse every 4 days, i.p.). This administration started at day 0 of Ang II (600 ng/kg/min, 14 days) infusion through an osmotic minipump or sham surgery. The graphs depict (a) CBF as percentage changes with respect to the initial CBF value, (b) resting CBF value and (c, d) represent 1 second average curves of the evoked CBF, expressed in arbitrary unit. SEM is represented by the lighter tone shade surrounding each curve. Data were analysed using ANOVA for factorial design followed by a Bonferroni post-test. ${ }^{* *} \mathrm{p}<0.01, \mathrm{n}=7-10$ per group. 


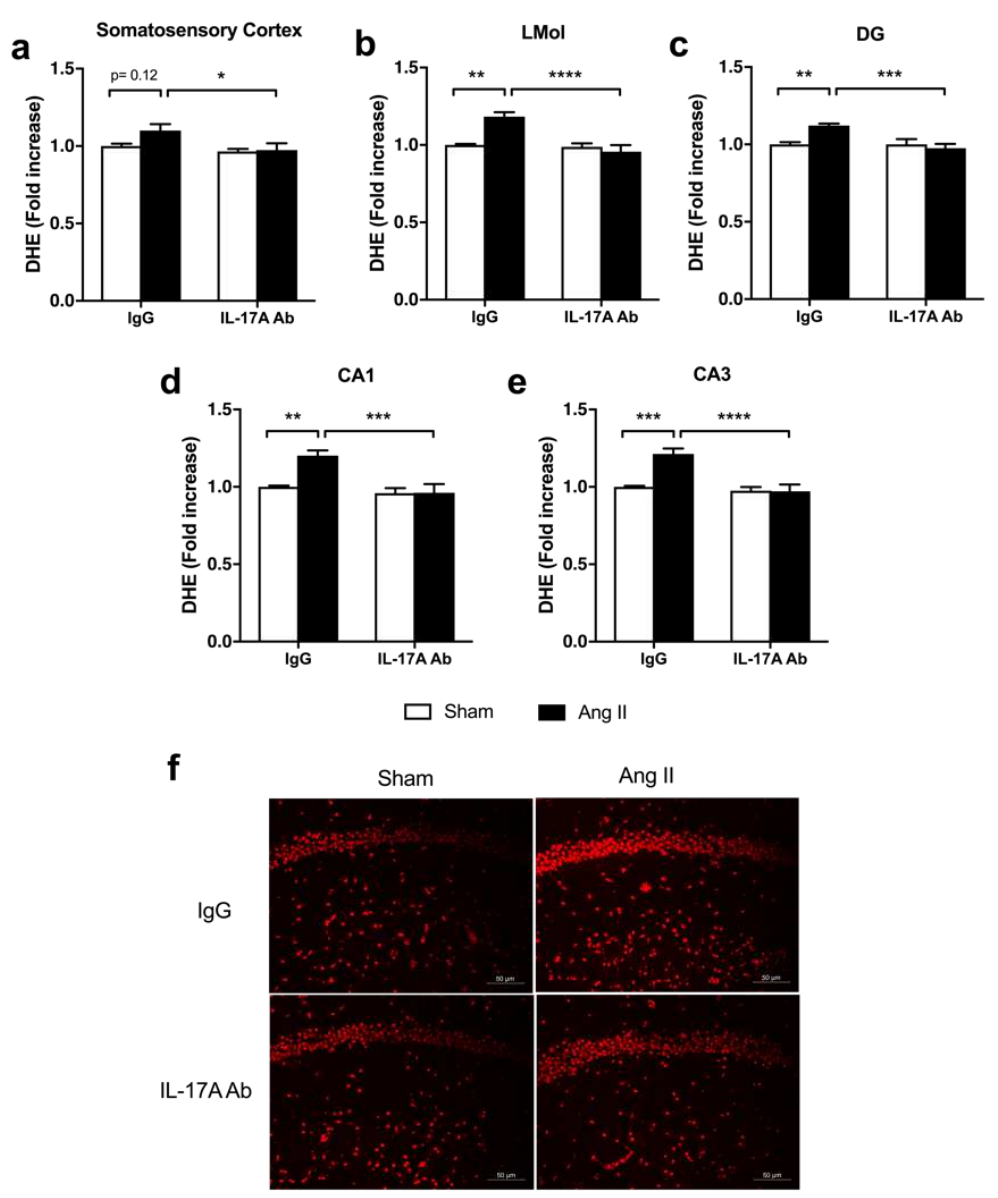

Figure 3: IL-17A neutralization prevents Ang II-induced oxidative stress production.

Superoxide anion production quantified using dihydroethidium fluoromicrography (DHE) in C57BL/6 male mice treated with an anti-IL-17 neutralizing antibody (IL-17A Ab) or control mouse immunoglobulin $\mathrm{G}(\mathrm{IgG})$ antibody $(0.5 \mu \mathrm{g} / \mu \mathrm{L}$ per mouse every 4 days, i.p.). This administration started at day 0 of Ang II (600 ng/ $/ \mathrm{kg} / \mathrm{min}, 14$ days) infusion through an osmotic minipump or sham surgery. The graphs depict the ratio of fluorescence compared to control mice in the (a) somatosensory cortex and different regions of the hippocampus: (b) lacunosum moleculare (LMol), (c) dentate gyrus (DG), (d) cornu ammonis 1 (CA1) and (e) cornu ammonis 3 (CA3). (f) Representative micrographs of DHE staining in CA1 of the hippocampus (50 $\mu \mathrm{m}$ scale). Data were analysed using ANOVA for factorial design followed by a Bonferroni posttest. ${ }^{*} \mathrm{p}<0.05,{ }^{* *} \mathrm{p}<0.01,{ }^{* * *} \mathrm{p}<0.001$ and ${ }^{* * * *} \mathrm{p}<0.0001 ; \mathrm{n}=7-10$ per group. 


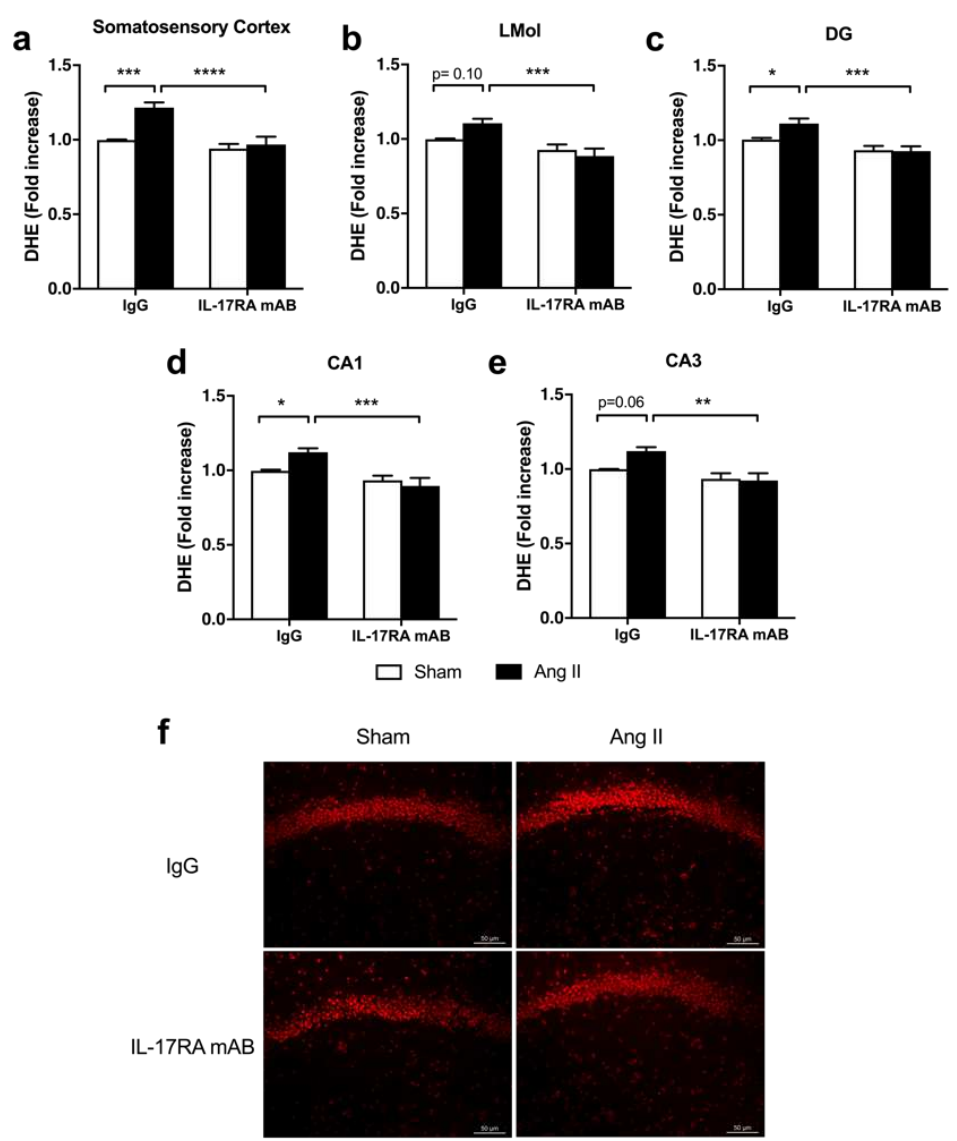

Figure 4: IL-17A receptor inhibition prevents oxidative stress production induced by Ang

II. Superoxide anion production quantified using dihydroethidium (DHE) fluoromicrography (DHE) in C57BL/6 male mice treated with an IL-17A receptor antagonist (IL-17RA mAB) or control mouse immunoglobulin $\mathrm{G}(\mathrm{IgG})$ antibody $(0.5 \mu \mathrm{g} / \mu \mathrm{L}$ per mouse every 4 days, i.p.). This administration started at day 0 of Ang II (600 $\mathrm{ng} / \mathrm{kg} / \mathrm{min}, 14$ days) infusion through an osmotic minipump or sham surgery. The graphs depict the ratio of fluorescence compared to control mice in the (a) somatosensory cortex and different regions of the hippocampus: (b) lacunosum moleculare (LMol), (c) dentate gyrus (DG), (d) cornu ammonis 1 (CA1) and (e) cornu ammonis 3 (CA3). (f) Representative micrographs of DHE staining in CA1 of the hippocampus (50 $\mu \mathrm{m}$ scale). Data were analysed using ANOVA for factorial design followed by a Bonferroni posttest. ${ }^{*} \mathrm{p}<0.05,{ }^{* *} \mathrm{p}<0.01,{ }^{* * *} \mathrm{p}<0.001$ and ${ }^{* * * *} \mathrm{p}<0.0001 ; \mathrm{n}=7-10$ per group. 

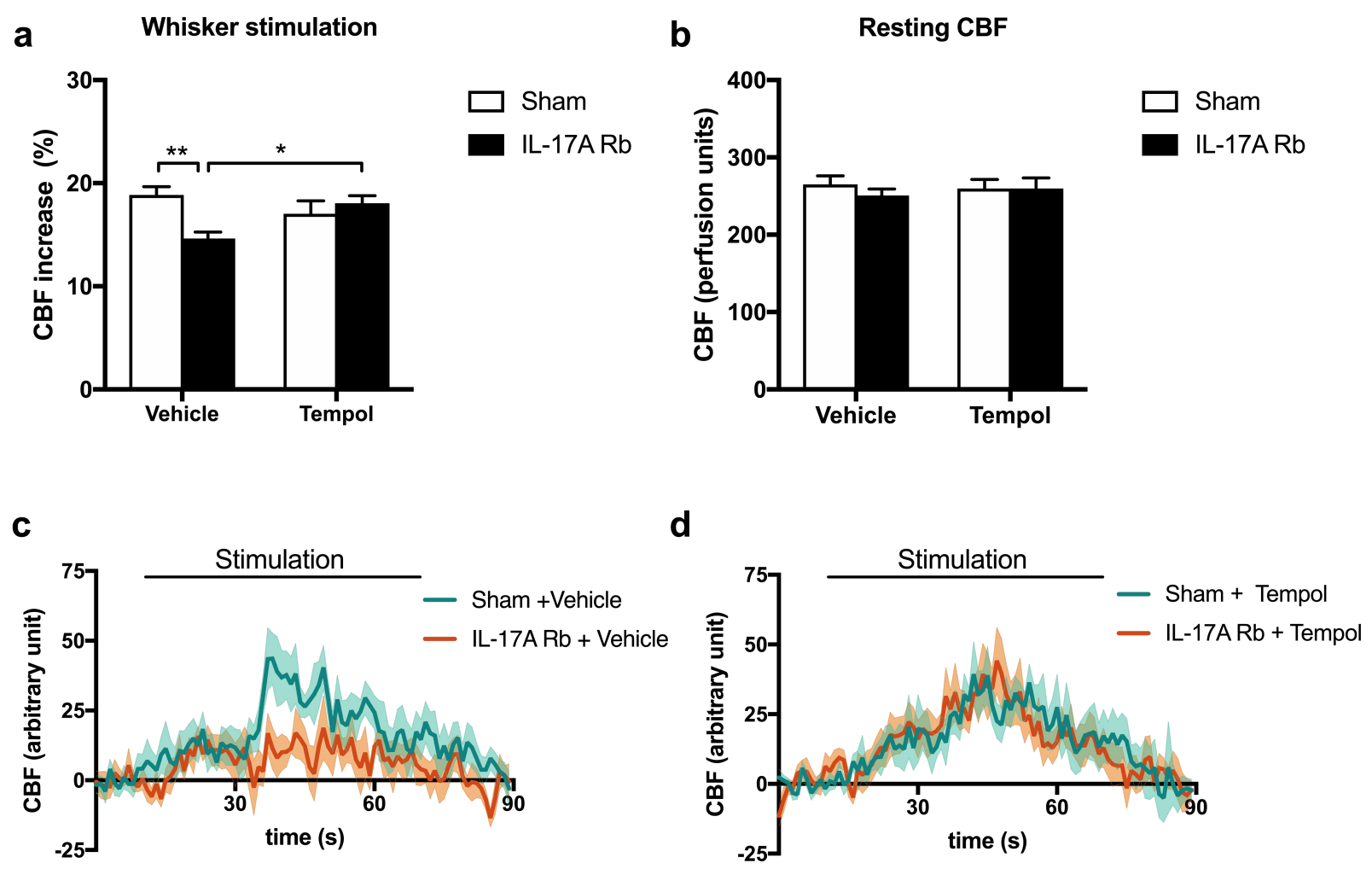

Figure 5: Tempol treatment prevents the neurovascular coupling alteration induced by IL17A. Cerebral blood flow (CBF) in response to whiskers stimulations measured in vivo by laser Doppler flowmetry in C57BL/6 male mice receiving IL-17A recombinant $(\mathrm{Rb})$ through an osmotic minipump (50 pg/kg/h, 7 days) and treated with or without Tempol ( $1 \mathrm{mM}$ changed every 2 days) administered in the drinking water. The graphs depict (a) $\mathrm{CBF}$ as percentage changes with respect to the initial CBF value, (b) resting CBF value and (c, d) represent 1 second average curves of the evoked CBF, expressed in arbitrary unit. SEM is represented by the lighter tone shade surrounding each curve. Data were analysed using ANOVA for factorial design with repeated measures followed by a Bonferroni post-test. ${ }^{*} \mathrm{p}<0.05,{ }^{* *} \mathrm{p}<0.01 \mathrm{n}=7-8$ per group. 

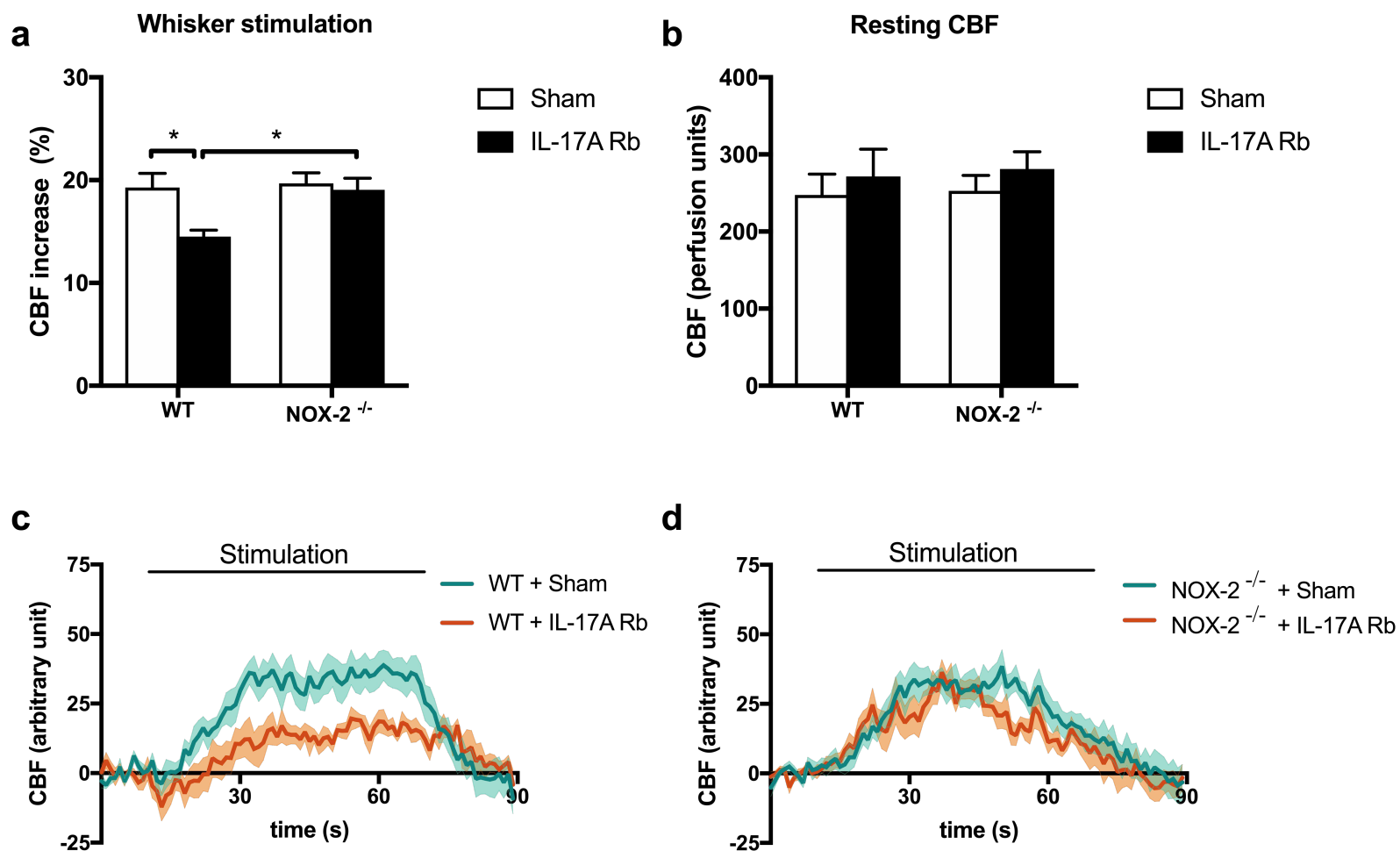

Figure 6: NOX-2 depletion prevents IL-17A-induced neurovascular coupling impairment.

Cerebral blood flow (CBF) in response to whiskers stimulations measured in vivo by laser Doppler flowmetry in NOX-2 ${ }^{-/}$or WT C57BL/6 male mice receiving IL-17A recombinant $(\mathrm{Rb})$ through an osmotic minipump (50 pg/kg/h, 7 days). The graphs depict (a) $\mathrm{CBF}$ as percentage changes with respect to the initial $\mathrm{CBF}$ value, (b) resting $\mathrm{CBF}$ value and (c, d) represent 1 second average curves of the evoked CBF, expressed in arbitrary unit. SEM is represented by the lighter tone shade surrounding each curve. Data were analysed using ANOVA for factorial design followed by a Bonferroni post-test. * $\mathrm{p}<0.05, \mathrm{n}=7-9$ per group. 

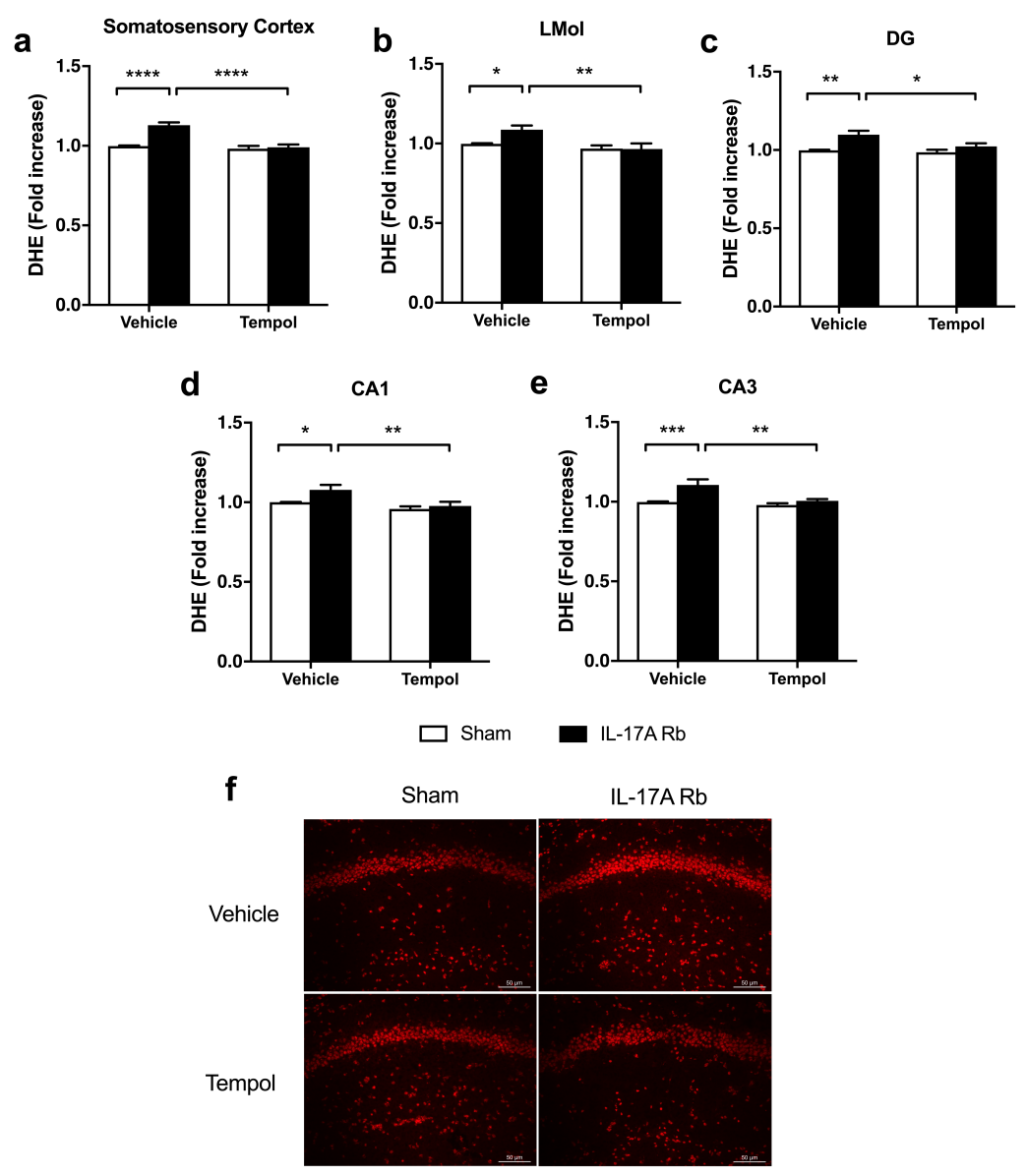

Figure 7: Tempol treatment prevents IL-17A-induced oxidative stress production.

Superoxide anion production quantified using dihydroethidium (DHE) fluoromicrography (DHE) in C57BL/6 mice receiving IL-17A Rb through an osmotic minipump (50 pg/kg/h, 7 days) and treated with or without Tempol ( $1 \mathrm{mM}$ changed every 2 days) administered in the drinking water. The graphs depict the ratio of fluorescence compared to control mice in the (a) somatosensory cortex and different regions of the hippocampus: (b) lacunosum moleculare (LMol), (c) dentate gyrus (DG), (d) cornu ammonis 1 (CA1) and (e) cornu ammonis 3 (CA3). (f) Representative micrographs of DHE staining in CA1 of the hippocampus (50 $\mu \mathrm{m}$ scale). Data were analysed using ANOVA for factorial design followed by a Bonferroni post-test. ${ }^{*} \mathrm{p}<0.05$, ${ }^{*} \mathrm{p}<0.01$, $* * * \mathrm{p}<0.001$ and $* * * * \mathrm{p}<0.0001 ; \mathrm{n}=6-7$ per group. 



Figure 8: NOX-2 depletion prevents oxidative stress production induced by IL-17A.

Superoxide anion production quantified using dihydroethidium (DHE) fluoromicrography (DHE) in $\mathrm{NOX}-2^{-/}$or WT C57BL/6 male mice receiving IL-17A Rb through an osmotic minipump (50 $\mathrm{pg} / \mathrm{kg} / \mathrm{h}, 7$ days). The graphs depict the ratio of fluorescence compared to control in the (a) somatosensory cortex and different regions of the hippocampus: (b) lacunosum moleculare (LMol), (c) dentate gyrus (DG), (d) cornu ammonis 1 (CA1) and (e) cornu ammonis 3 (CA3). (f) Representative micrographs of DHE staining in CA1 of the hippocampus (50 $\mu \mathrm{m}$ scale). Data were analysed using ANOVA for factorial design followed by a Bonferroni post-test. ${ }^{*} \mathrm{p}<0.05$, $* * \mathrm{p}<0.01, * * * \mathrm{p}<0.001$ and $* * * * \mathrm{p}<0.0001 ; \mathrm{n}=8-10$ per group. 

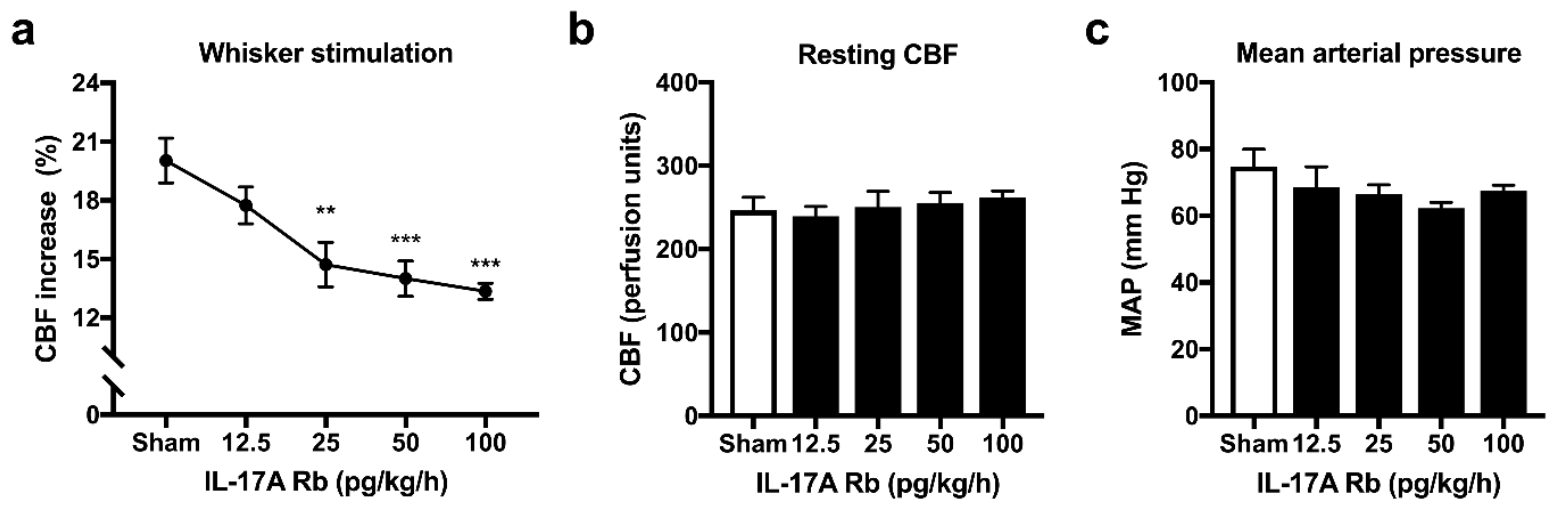

\section{Supplemental Figure 1 : Effect of chronic IL-17A administration on neurovascular}

coupling. CBF responses to whiskers stimulations measured in vivo by laser Doppler flowmetry in $\mathrm{C} 57 \mathrm{BL} / 6$ male mice receiving 12.5 to $100 \mathrm{pg} / \mathrm{kg} / \mathrm{h}$ of IL-17A Rb through an osmotic minipump (7 days) or sham surgery. The graphs depict (a) $\mathrm{CBF}$ as percentage changes with respect to the initial $\mathrm{CBF}$ value, (b) the resting $\mathrm{CBF}$ value, or (c) the mean arterial pressure monitored simultaneously with CBF. Data were analysed using one-way-ANOVA followed by Dunnet's post-test. ${ }^{* *} \mathrm{p}<0.01,{ }^{* * *} \mathrm{p}<0.001 \mathrm{n}=10-12$ per group. 

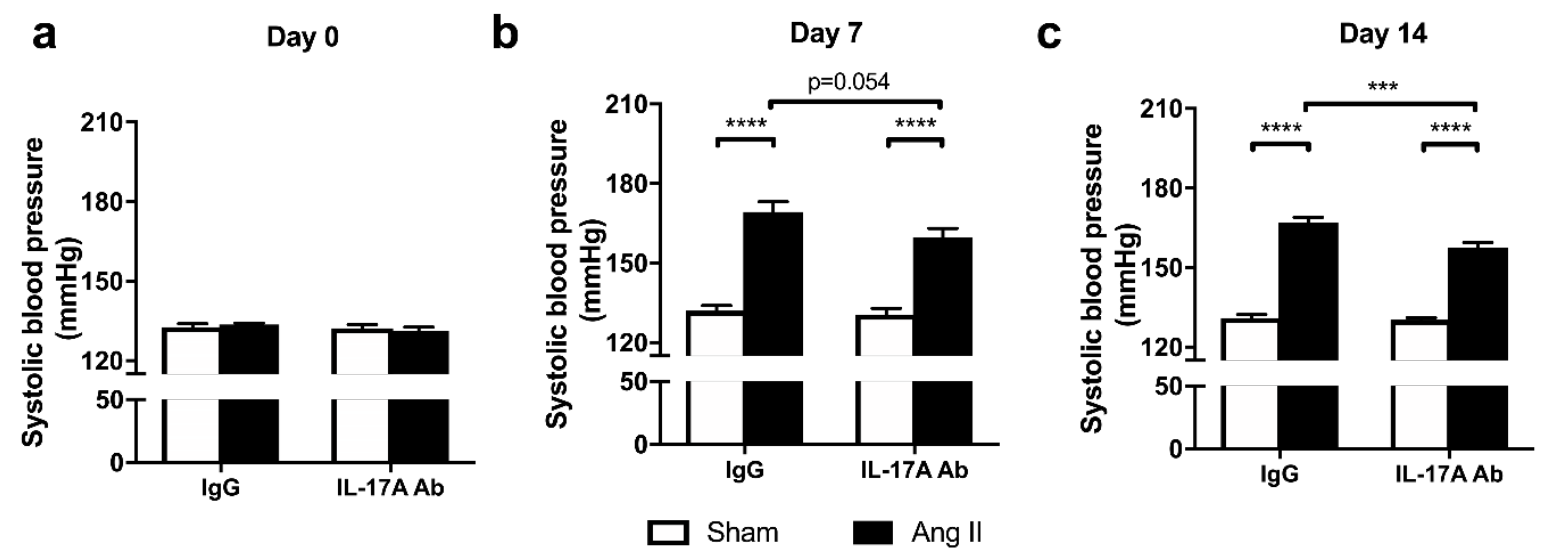

Supplemental Figure 2: IL-17A neutralization partially prevents the increased systolic

blood pressure induced by Ang II. Systolic blood pressure assessed at (a) day 0, (b) day 7 and

(c) day 14 by tail-cuff plethysmography in C57BL/6 male mice treated with an anti-IL-17A

neutralizing antibody (IL-17A Ab) or control mouse immunoglobulin G (IgG) antibody (0.5

$\mu \mathrm{g} / \mu \mathrm{L}$ per mouse every 4 days, i.p.). This administration started at day 0 of Ang II (600

$\mathrm{ng} / \mathrm{kg} / \mathrm{min}, 14$ days) infusion through an osmotic minipump or sham surgery. Data were analysed

using ANOVA for factorial design followed by a Bonferroni post-test., ${ }^{* * *} \mathrm{p}<0.001$ and $* * * * \mathrm{p}<0.0001 \mathrm{n}=11-18$ per group. 

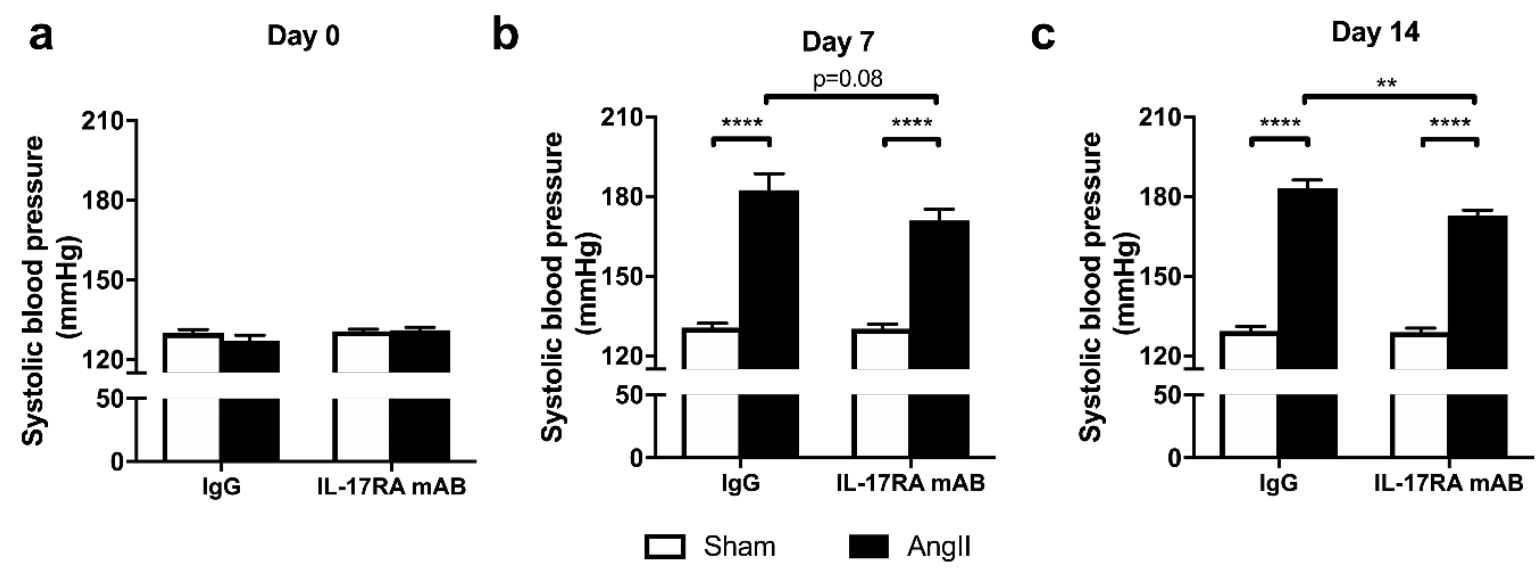

Supplemental Figure 3: IL-17A receptor inhibition partially prevents increased systolic

blood pressure induced by Ang II. Systolic blood pressure assessed at (a) day 0, (b) day 7 and (c) day 14 by tail-cuff plethysmography in C57BL/6 male receiving an IL-17A receptor antagonist (IL-17RA mAB) or control mouse immunoglobulin $\mathrm{G}(\mathrm{IgG})$ antibody $(0.5 \mu \mathrm{g} / \mu \mathrm{L}$ per mouse every 4 days, i.p.). This administration started at day 0 of Ang II (600 ng/kg/min, 14 days) infusion through an osmotic minipump or sham surgery. Data were analysed using ANOVA for factorial design followed by a Bonferroni post-test. ${ }^{* *} \mathrm{p}<0.01$ and ${ }^{* * * *} \mathrm{p}<0.0001 \mathrm{n}=9-13$ per group. 
a

Day 0



Sham b

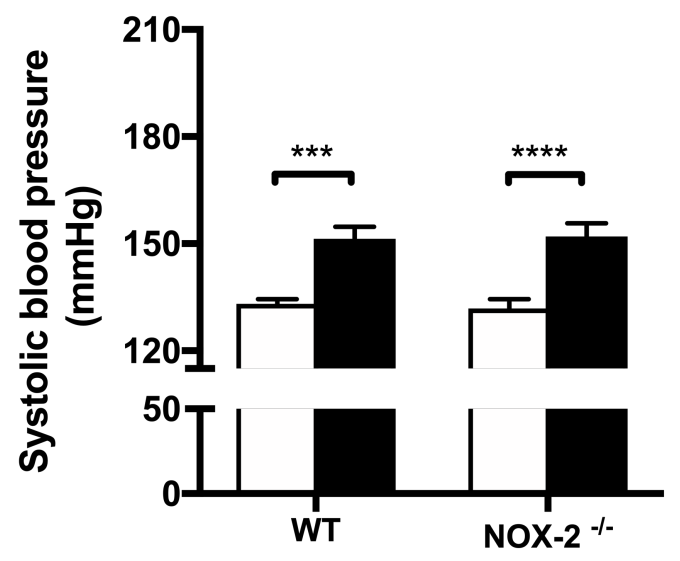

IL-17A Rb

Supplemental Figure 4: Effect of NOX-2 depletion on systolic blood pressure increase induced by chronic IL-17A Rb administration. Systolic blood pressure assessed at (a) day 0 and (b) day 7 by tail-cuff plethysmography in NOX-2 $\%$ or WT C57BL/6 male mice receiving IL-17A Rb through an osmotic minipump (50 pg/kg/h, 7 days). Data were analysed using ANOVA for factorial design followed by a Bonferroni post-test. ${ }^{* * *} \mathrm{p}<0.001,{ }^{* * * *} \mathrm{p}<0.0001$ $\mathrm{n}=8-10$ per group. 